\title{
O que está a mudar no Português Europeu?
}

\section{What is Changing in European Portuguese?}

\author{
Maria Carmen de Frias e Gouveia [mariacarmen.defriasegouveia@gmail.com] \\ Faculdade de Letras da Universidade de Coimbra / CELGA-ILTEC, Portugal
}

\section{RESUMO}

Partindo da teoria da mudança linguística e da observação da realidade mais recente dos usos linguísticos do Português Europeu, pretende-se chamar a atenção, sobretudo dos professores/estudantes de Língua Portuguesa como Língua Não Materna, para as mudanças que ocorreram ou estão a ocorrer no idioma contemporâneo. Inicialmente verificadas na língua oral, muitas alterações se têm vindo a verificar e difundir, essencialmente nos planos morfológico (género gramatical, flexão verbal) e da sintaxe (estruturas comparativas, gerúndio com preposição, etc.). Após uma apresentação dessas mudanças (já estabilizadas ou em curso), far-se-á uma reflexão sobre o modo como devem ser entendidas e abordadas no ensino/aprendizagem da Língua Portuguesa.

\section{Palavras-Chave}

Variação sincrónica; mudança linguística; género gramatical; estruturas comparativas; particípios duplos; gerúndio; conjuntivo

\begin{abstract}
Starting from the theory of linguistic change and the observation of the most recent reality of the linguistic uses of European Portuguese, it is intended to draw attention, mainly from the teachers / students of Portuguese Language as Non-Mother Language, to the changes that have occurred or are occurring in the contemporary language. Many changes have been noticed (mainly in spoken language) and are spreading, essentially in what concerns the following linguistic areas: morphology (grammatical gender), syntax (comparative structures, gerund with preposition, relative pronouns) and syntax and semantics (verbal tense and mood).After a presentation and explanation of these changes (either already stabilized or in progress), there is a reflection on how they should be understood and dealt with in Portuguese language teaching / learning.
\end{abstract}

\section{KEYWORDS}

Synchronic variation; linguistic change; grammatical gender; comparative structures; double form participles; gerund; subjunctive

RECEBIDO 2019-06-26; ACEITE: 2019-07-30

Por razões pessoais e, sobretudo, científicas, neste texto não se segue o "novo" Acordo Ortográfico da Língua Portuguesa de 1990. 


\section{Introdução}

A ideia subjacente a este trabalho está na observação de que, com frequência, se encontram, na língua oral e escrita do Português Europeu contemporâneo, variações e desvios/alterações que, como referem João Peres e Telmo Móia (1995: 41), “ora [...] a comunidade rejeitará, ora [podem ser] sintomas de evolução que possivelmente vingarão" ${ }^{1}$.

No presente estudo, e dado que os interesses que têm norteado a minha investigação até ao momento se centram nas áreas da História da Língua Portuguesa e da Variação, afigura-se de grande pertinência descrever, explicar e analisar também desvios/ variações que se vêm verificando, e que têm implicações no ensino do Português como Língua Não Materna.

O motivo da selecção das estruturas que estão na base deste trabalho prende-se com uma observação feita ao uso que as mesmas estão a ter por parte dos falantes da língua portuguesa europeia, parecendo haver - nas últimas décadas - uma clara simplificação, recorrente na utilização que os falantes delas fazem no dia-a-dia e em vários contextos situacionais (que não apenas o da linguagem informal/familiar).

Os objectivos são, assim, descrever, explicar e analisar a consistência da variação existente nos vocábulos ou estruturas considerados, no sentido de tentar entrever se verdadeiramente se trata de uma mudança ou de meras tendências que poderão reverter-se e, simultaneamente, reflectir sobre o que o professor de língua deve fazer ao ensinar as estruturas/ particularidades linguísticas que estão/podem estar a sofrer mudança.

\subsection{Enquadramento teórico-metodológico: variação e mudança linguística}

É um ponto assente que as línguas são dotadas de variação, em dois planos (diacrónico e sincrónico), e que a mesma pode ocorrer a nível diatópico, diastrático e diafásico.

A relação entre variação e mudança estabelece-se, como é sabido (cf. Coseriu 1958 ou as aportações da teoria sociolinguística ao estudo da mudança, exposta em Weinreich, Labov e Herzog, 1968, por exemplo) somente quando uma das estruturas/ palavras/ unidades fonológicas, etc., em concorrência é considerada como mais prestigiada pela comunidade de falantes, passando a ser a preferida, e conduzindo à generalização de uso. A sua concorrente fica, deste modo, relegada para uma situação de segundo plano (originando, muitas vezes, que se torne arcaizante e/ou desapareça).

Pode, igualmente, ocorrer variação sem que a mudança aconteça. No entanto, o inverso não é verdadeiro: para que se efectue a mudança linguística terá que ter existido, num determinado momento (normalmente num processo longo, por vezes secular), uma variação.

Tendo em conta o que acaba de referir-se, neste estudo seguir-se-á uma análise descritiva, mas sob o referido escopo da teoria da mudança linguística e da Sociolinguística Histórica que lhe está associada, pois a variação pode estar confinada a diferentes estratos sociais, diversos níveis etários, o que norteará ou não a sua fixação em mudança.

1 Os Autores estudaram, fundamentalmente, estruturas argumentais, construções passivas, construções de elevação, orações relativas, construções de coordenação e concordâncias. 


\subsection{As estruturas consideradas}

Distinguiram-se dois tipos de situações, que se tratarão em pormenor na secção 3: os casos em que as descrições gramaticais mostram haver consciência da variação:

- estruturas comparativas de superioridade e inferioridade,

- Particípio Passado: uso das formas duplas com o verbo TER,

— estratégia "cortadora" em estruturas relativas;

e outros aspectos que revelam já alguma consistência que anuncia a mudança, mas que são mais raramente referidos:

- género de vocábulos terminados em -a,

- (em) fazendo: supressão da preposição que marca a anterioridade imediata de uma acção face ao verbo principal,

- uso preferencial dos tempos simples dos modos Conjuntivo e Infinitivo em lugar dos compostos, ao invés do que ocorre com o modo Indicativo.

\section{O corpus e metodologia de tratamento dos dados}

Partiu-se do que as gramáticas normalmente estipulam no que se refere ao uso das estruturas seleccionadas, procedeu-se à análise propriamente dita dos dados, ora extraídos de textos jornalísticos (com dados recolhidos nos corpora do jornal $P$ úblico ${ }^{2}$ ), mais próximos da linguagem quotidiana, e observou-se igualmente as produções orais ouvidas a falantes nativos de Português Europeu, dado que a oralidade constitui, como se sabe, a principal fonte de mudança.

Como os textos de que se extraíram os exemplos são de inícios dos anos 90 e os objectivos do trabalho pressupunham verificar os desvios/alterações que estão em curso na língua hodierna, sob a perspectiva da variação e mudança linguística, procedeu-se, igualmente à pesquisa de dados dos anos 2016-2018, uma vez que importava confirmar se num lapso temporal de cerca de 25 anos teria havido maior generalização das alterações que se verificavam já em 1991 e/ou se essa variação já se estaria a consolidar na norma. Desse modo poderá compreender-se melhor as eventuais alterações que tiveram lugar ao longo do período em apreço (1991-2016 e, para confirmação dos dados, últimos meses de 2018).

Os dados recolhidos foram analisados separadamente por cada ano e cada estrutura, com os respectivos exemplos.

2 Os dados para a análise foram extraídos do corpus NaturaPublico, nomeadamente nos dois acervos de textos completos de NaturaPublico91 e NaturaPublico94, corpus esse que contém os dois primeiros parágrafos de cada artigo publicado no jornal Público no primeiro trimestre dos anos 1991 a 1994, e que se encontra disponível no endereço eletrónico http://natura.di.uminho.pt/jjbin/corpora. O acervo de dados do NaturaPublico é constituído por 525.465 (1991) e 1.515.353 (1994) palavras, respectivamente, o que dá uma ideia da dimensão desse "corpus" e pode ajudar a compreender alguns dos valores numéricos que adiante se apresentam. 


\section{O que dizem as Gramáticas}

\subsection{Estruturas comparativas de superioridade e inferioridade}

As gramáticas de língua portuguesa editadas entre 1984 e 2013 já todas referem a possibilidade de omissão de do nas orações comparativas de superioridade e inferioridade ${ }^{3}$. Deste modo procedem Cunha e Cintra (1984: 257 e 544), Mário Vilela (1999: 235), no quadro-síntese, ainda que prefira a não omissão, e Maria Helena Mira Mateus et al. (2003: 732-33).

Mais recentemente, Paiva Raposo et al. (2013: 1588), ainda que pareçam aconselhar o uso, no segundo segmento da comparação, de DO QUE, referem, claramente, na nota 33 dessa mesma página, que «para alguns falantes, a forma do pode ser omitida [...]”. E, mais adiante (2013: 2152): "Quer o operador comparativo de superioridade, quer o de inferioridade selecionam a sequência do que Or[ação] ou que Or. Em comparativas frásicas, a forma do que é obrigatória (ex. * $\mathrm{O}$ temporal chegou mais depressa que se esperava), enquanto em comparativa sintagmática há opcionalidade entre a forma do que e a forma que" (cf. também Mira Mateus et al.): O Paulo chegou mais depressa (do) que eu.».

Tendo em conta que, até ao momento, se assiste a uma verdadeira variação de uso, importa agora ver se essa variação se mantém inalterada ao longo dos últimos anos ou, se - ao invés - a variação se está a concretizar num processo de mudança.

\subsection{Particípios duplos}

O emprego das formas duplas de Particípio Passado ${ }^{4}$ está igualmente a sofrer variação: as formas outrora usadas com os auxiliares ser, estar e ficar, são agora vulgarmente acompanhadas por ter (por ex. ter morto, ter salvo, etc.)

Para Bechara (2001: 230),

Em geral emprega-se a forma regular, que fica invariável com os auxiliares ter e haver, na voz ativa, e a forma irregular, que se flexiona em gênero e número, com os auxiliares ser, estar e ficar, na voz passiva. [...] Há outros particípios, regulares ou irregulares, que se usam indiferentemente na voz ativa (auxiliares ter e haver) ou passiva (auxiliares ser, estar [,] ficar), [... $]^{5}$.

Uma década mais tarde, Raposo (2013: 32-34) e colaboradores têm perfeita consciência da mudança em progresso ${ }^{6}$, que explicam do seguinte modo:

3 Preferiu-se a designação de estruturas a orações, como Ana Alexandra Silva (2003: 744), uma vez que «a comparação deve ser entendida como um signo dotado de dupla face: o significado (o sentido veiculado incluirá uma comparação entre dois termos) e o significante (estruturas formais traduzidas em segmentos como: mais ... (do) que..., menos ... (do) que, etc.».

4 Sobre os particípios duplos do Português poderá consultar-se, por ex., Ferreira, 2013.

5 E Bechara (2001: 230) especifica ainda: "Há uns poucos particípios irregulares terminados em -e, em geral de introdução recente no idioma: entregue (o mais antigo), aceite, assente, empregue (em Portugal)".

6 "Um [...] caso de nivelação analógica portuguesa que, aliás, ainda está em curso, é o dos verbos abundantes. São 
A existência destes e de outros pares morfológicos, integrados por palavras tanto regulares como irregulares, é muito comum ao nível da aquisição da linguagem, nível esse em que se pode produzir, inclusivamente, um efeito de bloqueio a favor das formas irregulares. Já entre falantes adultos, os pares morfológicos e a instabilidade de uso de uma ou outra das suas formas são reflexo de uma mudança em curso. Em português, por exemplo, a mudança em causa é provavelmente sintática e envolve as construções com verbos auxiliares. Cada vez mais os falantes se afastam da prescrição da gramática tradicional que regula, geralmente, o uso dos particípios fortes (por serem adjetivais) com os verbos ser e estar, e o dos particípios fracos (por serem verbais) com o verbo ter dos tempos compostos.

Notam ainda que se ouve, com frequência, hoje em dia, "certas construções ativas como a equipa tem ganho muitos jogos, os agentes tinham preso muitos indivíduos ou os bombeiros terão extinto os fogos todos, prova de que há alguma mudança em curso nesta área, com o particípio fraco a ceder terreno à forma forte" (2013: 33) ${ }^{7}$.

Raposo e colaboradores observam igualmente “já o 'triunfo consumado’ de pago e limpo”. E, no vol. II (2013: 1490), os mesmos Autores afirmam:

Estas regras, ainda que cubram de forma geral a distribuição dos dois tipos de particípios, são algo normativas, e não são seguidas por todos os falantes. Em particular, nos contextos em que as gramáticas prescrevem o uso de formas regulares - ou seja, nos tempos compostos -, é frequente o emprego de particípios curtos. No entanto, existe bastante variação entre os falantes quanto às formas usadas, ou mesmo quanto às possibilidades de uso. $[\ldots]^{8}$.

Concluem (2013: 1492), então: "Para a maioria dos falantes - admitindo embora que possa haver alguma variação de uso -, estas formas curtas têm apenas propriedades adjetivais, visto que não podem ser usadas em contextos onde predomina a natureza verbal do particípio - ou seja, nos tempos compostos e nas orações passivas"

verbos com particípios duplos no seu paradigma, ou seja, têm duas formas diferentes para o particípio passado: a forma rizotónica (também dita forte), com acento no radical e irregular do ponto de vista da sua formação morfológica (p.e., ganho, preso, extinto), e a forma arrizotónica (também dita fraca), com acento na vogal temática e portanto regular, já que tem o sufixo -do acrescentado ao tema verbal (p.e., ganhado, prendido, extinguido). As formas fortes têm, desde o latim, um estatuto gramatical mais próximo do de nomes e adjetivos do que do estatuto de verbos" (p. 32-33).

7 Surgiam igualmente, em Português antigo, formas como abrido: registei, em 1457, em documento de Coimbra, "que o dicto oliual fosse laurado e abrido, estrecado e amotado". Esta forma, não rara nesse século, coexistia com aberto (< APERTU-), que se encontra desde cedo na língua.

8 Há, contudo, algumas restrições, que os mesmos AA notam: em frases passivas "O veículo foi submerso" menos aceitável que foi submergido (cf. nota 173 da p. 1491) e acrescentam que "[...] existem formas que morfologicamente se relacionam com particípios curtos de verbos transitivos, mas que apenas podem ser usadas em contextos copulativos e não em orações passivas ou em tempos compostos". (A roupa está seca, mas não a roupa foi seca). Cf. pp. 1491-2. Também é mais comum "ficar surpreendido/a" do que surpreso/a. 


\subsection{Relativo "quem"}

Peres e Móia (1995: 269-369), ao tratarem das orações relativas, já observam (p. 277) que "o português actual parece estar também a assimilar a tendência [...] para simultaneamente neutralizar o pronome relativo [...] e deixar vazia a posição por ele ligada.”

Aliás, na p. 288 dedicam-se, precisamente, à supressão da preposição DE do constituinte relativo, numa normalmente denominada "estratégia cortadora", e exemplificam com: "O autor português que eu mais gosto é o Aquilino" ou, retirado de um texto jornalístico da segunda metade dos anos 80, "[...] um Governo em condições piores dos que as que dispõe actualmente" (O Jornal, Agosto 1986).

Cunha e Cintra (1984: 350) notam que com "referência a um antecedente explícito, quem equivale a "o qual" e vem sempre antecedido de preposição".

No entanto, Peres e Móia (1995: 277) já registam o uso dessa estrutura sem a preposição e com emprego de que:

A rapariga que te falei ontem arranjou um emprego na Covilhã (em vez de "de quem")

A única zona da cidade que o povo tem algum orgulho é este jardim. (= de que / em que)

O santo português de que(m) se comemora hoje o aniversário do nascimento é São Frutuoso. (1995: 323).

Com efeito, uns anos mais tarde, Mira Mateus et al. (2003: 662) observa que "O relativo que é sem dúvida um dos mais polivalentes".

Também Paiva Raposo et al. (2013: 2089-90), referem que "quem", dado o seu traço humano, surge em relativas de nome e não de frase. Na p. 2085 exemplificam-se alguns casos nos quais "quem" com preposição é substituído por "que":

A Ana, de que te falei ontem.

Segundo os AA., nas apositivas prefere-se "quem", mas aparece "que", com "estratégia cortadora" (2128-9):

Não havia dia nenhum que (= em que) $\ldots$

Cada sítio que nós íamos (= a que)

O envolvimento que (= de que) eu falei.

As pessoas com que (= com quem) saí.

Constituinte relativo preposicionado com função de complemento indirecto:

O idiota a que (= a quem) emprestei o livro

"Esta preferência é mais acentuada relativamente a quem preposicionado, quando o antecedente é [+ humano], sobretudo na função de complemento indireto [...]” (p. 2083). 


\subsection{Outros aspectos em mudança}

\subsubsection{Género}

A influência da terminação para a atribuição do género é muitas vezes determinante nouso que os falantes fazem, tanto os aprendentes estrangeiros como os nativos de Português. Até os falantes mais cultos são, por vezes, "contagiados" por esse emprego, não raras vezes anómalo (deveria dizer-se o amálgama e não $a$, por exemplo). Aliás, as palavras de terminação -ma com origem grega deveriam ser masculinas. Contudo, o facto de terminarem em -a leva a identificá-las com o género feminino, tendo algumas delas acabado por se fixar como tal. Amálgama, palavra inicialmente masculina ou ambígua nos dicionários, passou a ter os dois géneros nos anos 90 e, em 2004, o Dicionário da Porto Editora estabelece o feminino (Gouveia 2011: 87), o mesmo ocorrendo com cataplasma. Grama, ainda que preferencialmente masculina nos dicionários, a nível oral é mais comummente feminina: *duzentas gramas".

Diabetes, entorse, por exemplo, são ambíguos, pelo que a variação irá levar a uma escolha por um género ou por outro.

\subsection{2. (Em) fazendo}

Esta estrutura "marca enfaticamente a anterioridade imediata da acção com referência ao verbo principal", como referem Cunha e Cintra (1984: 489), sendo o equivalente a "Depois de + infinitivo".

$\mathrm{Na}$ oralidade, sobretudo, tem-se vindo a verificar a elipse da preposição, sendo cada dia mais frequente, por exemplo, "Terminando a aula, vamos almoçar" em lugar de "EM terminando a aula, vamos almoçar".

\subsubsection{Tempos compostos do Conjuntivo e Infinitivo}

Ao contrário do que ocorre com o modo Indicativo, em que os vários tempos compostos são largamente utilizados, por serem muitas vezes insubstituíveis, como é o caso do Pretérito Perfeito Composto (que se refere a uma acção antes iniciada e que vem ininterruptamente até ao presente, podendo continuar no futuro: “Tenho trabalhado muito este ano."), ou por terem relegado o tempo simples para a escrita literária ou mais cuidada (por exemplo, o Pretérito Mais-que-Perfeito Simples cedeu terreno ao Composto: é raro ouvir dizer "Ele tivera uma vida difícil" e sim "Ele tinha tido uma vida difícil”), nos modos Conjuntivo e Infinitivo eles são muitas vezes preteridos em benefício do tempo simples.

Ainda que se continuem a usar os tempos compostos desses dois modos verbais, a verdade é que cada vez mais se simplificam, sendo usuais estruturas do tipo "Se o visse, dizia-lhe para jantar connosco" ainda que se esteja a referir uma acção irreal, que não aconteceu, e que poderia ser traduzida por "Se o tivesse visto, tinha-lhe dito...".

Aliás, o Pretérito Imperfeito do Conjuntivo substitui, não raras vezes os vários tempos compostos do Conjuntivo, à excepção do Futuro Composto que somente é negligenciado em favor do 
Futuro Simples do Conjuntivo ("Quando tiverem terminado o exercício podem sair”> "Quando terminarem o exercício podem sair”).

O mesmo ocorre com o modo Infinitivo, em que é cada dia mais comum ouvir-se, mesmo para uma situação que não ocorreu, “Gostava de o ver!” (em lugar de “Gostava de o ter visto!”).

Parece, portanto, que se trata de uma situação de economia linguística, por simplificação de uso quando há como opção mais do que uma estrutura: os falantes preferem, normalmente, a que lhes causa menor esforço ou dificuldade de emprego.

\section{Análise dos dados obtidos}

\subsection{Estruturas Comparativas}

Foram seleccionadas como exemplo estruturas com "mais (do) que" e "menos (do) que", cujas ocorrências foram contabilizadas em separado, sendo quatro na prática - com e sem a denominada "estratégia cortadora" -, utilizando para tal a pesquisa no menu de edição do Público e procedendo à confirmação do uso de cada atestação:

\section{Mais do que}

1991:

(1) O grupo não deverá ter mais do que três pessoas, todas elas da máxima confiança de Jorge Sampaio.

(2) "Uma Mulher Só" trata o tema, hoje em dia mais do que corriqueiro, do cônjuge que se vê confrontado com a iminência do divórcio.

1994:

(3) Mas o resultado final é mais do que uma cópia desses grupos.

(4) A autora é hoje docente na Universidade de Lisboa e, mais do que isso, destacada especialista em estudos vicentinos.

2016: não se encontraram resultados.

\section{Mais que}

1991:

(5) Leu o texto de Miguel Torga mais que uma vez.

(6) Poucos esperariam, no entanto, que a equipa de Carlos Garcia fosse capaz de ontem ir ao Bessa jogar para conseguir algo mais que o empate. 
1994:

(7) O pior é que as organizações ganham mais que os futuros artistas e os regulamentos produzem mais vícios que arte.

(8) Uma viagem curta que, ao fim-de-semana, de carro, se faz em cinco minutos e custa pouco mais que 500 escudos.

2016:

(9) os malefícios e inconvenientes de, em Portugal, um livro escolar servir para uso de mais que um aluno $[\ldots]$

(10) enquanto os vinhos brancos não representam mais que $15 \%$ da produção total.

NB. Não deixa de ser significativo que, numa mesma frase, coexistam as duas estruturas, como nesta abonação de 1991, o que traduz já uma hesitação no seu emprego:

(11) O observatório registou, no ano passado, 68 sismos significativos em todo o mundo, oito a mais que em 1989 e seis a mais do que a média anual da década de 1980.

\section{Menos do que}

1991:

(12) Cerca de três mil trabalhadores da Direcção Geral das Contribuições e Impostos ganham hoje menos do que em 1989.

(13) na América do Sul, onde nada menos do que 63 milhões de pessoas vivem sem saneamento básico.

1994:

(14) Zurique cresceu menos do que outras praças europeias.

(15) Se os seus rendimentos ultrapassam 1760 contos, então vai poder deduzir menos do que em 1993 e, assim, pagará mais impostos.

2016: não se registaram resultados.

\section{Menos que}

1991:

(16) a edição destes clips tem por agora custos que não permitem lançá-los no mercado por muito menos que os programas visuais de longa duração.

(17) o F.C. Porto conseguiu, enfim, dar uma volta completa no marcador, o que nestes jogos decisivos $[\ldots]$ é pouco menos que milagre. 
1994:

(18) É bastante menos que o custo da abertura de Lisboa Capital da Cultura.

(19) Há 20 anos, em Itália, as autoridades fizeram ainda menos que Gorbatchov.

2016:

(20) Duarte Pacheco realçou (...) que a economia cresce este ano e em 2017 menos que em 2015.

(21) A venda, realizada a 7,90 euros por acção, $8,6 \%$ menos que a última cotação, gerou na sessão desta sexta-feira um ajustamento do título para esse valor [...].

No segundo semestre de 2018 ainda surge, esporadicamente, mais do que:

(22) Propostas dos partidos chegam mais depressa a leis do que as do Governo.

Contudo, mais que (só numa rápida pesquisa em títulos de notícias, ainda que se possa argumentar que o facto de serem recorrentemente mais sucintos poderia condicionar a estrutura) continua esmagadoramente frequente:

(23) Vistos Gold: investimento chinês cai, turco mais que duplica.

(24) Hugo Pinto: Jamor 365 é muito mais que uma marca.

(25) Muito mais que Weinstein: um ano de MeToo é passar de "me" para todos.

Não deixa de ser interessante o seguinte registo (4/10/2018), pois nele coexistem os dois tipos de estrutura (canónica e "cortadora"), com menos que, mas mais do que:

(26) $[\ldots]$ quando a taxa de glicose no sangue diminui para valores inferiores aos normais, normalmente causados pelos doentes comerem menos que o habitual ou colocarem doses mais altas de insulina do que realmente o corpo precisa.

\subsection{Formas "curtas" de Particípio Passado com o auxiliar ter ${ }^{10}$}

1991:

(27) $[\ldots]$ depois de ter aceite o pedido de demissão apresentado [...].

(28) O primeiro-ministro desmentiu, ontem, que o Governo português tenha recentemente expulso $[\ldots]$ diplomatas soviéticos.

10 Seleccionaram-se somente alguns exemplos por contenções de espaço, sendo cada vez mais frequentes as formas curtas a partir de 1994. 
1994:

(29) Bill Clinton revela ter aceite o pedido de demissão «com profunda consternação».

(30) Constâncio teria aceite ontem o convite mas, em contrapartida, colocou condições.

Contudo, encontra-se igualmente o uso "canónico" com as formas tradicionais:

1994:

(31) Tinha aceitado participar nesse encontro de escritores de língua portuguesa [...].

(32) tendo [...] os países em desenvolvimento aceitado que essas questões possam ser levantadas $[\ldots]$.

Em 2016 (último trimestre), ainda que a forma curta fosse muitíssimo mais frequente, ainda foi possível registar 21 abonações. Além do verbo aceitar, pesquisou-se outros verbos, não se tendo atestado qualquer forma de salvado. Por sua vez, elegido atesta-se em 8 situações, 7 delas canónicas:

(33) O PS venceu as eleições legislativas regionais, com maioria absoluta, no dia 16 de Outubro, tendo elegido 30 deputados.

(34) "Não fiquei, por isso surpreendida, ao ver que ele tinha elegido [...] os motivos relacionados com a família e a infância”.

Eleito/a documenta-se, como seria expectável, com o verbo ser:

(35) Extrema-direita à frente da CDU na região por onde Merkel é eleita.

Desviante é, contudo, a atestação seguinte:

(36) Foi no âmbito do seu mestrado que teve acesso aos laboratórios do Imperial College, em Londres, local elegido pela criadora para testar o produto.

Em 2018 a tendência manteve-se, não obstante o facto de ainda se atestarem 13 casos de salvado, como por exemplo:

(37) Marchionne [...] ficou conhecido por ter salvado a Fiat da bancarrota em 2004.

(38) $\mathrm{O}$ acesso às modestas receitas que gera [...], teria salvado o Museu. 


\subsection{Estratégia "cortadora" e simplificação / neutralização em "que" em estruturas re- lativas}

O corpus escrito revela ainda vários exemplos com a estrutura normativa, tal como se atesta em 1994: "encontram livros de que gostam ou escreve não sobre uma área musical, mas sobre tudo aquilo de que gosta."

No mesmo ano, contudo, «Existem elementos em vários campos musicais, e não só no rock, que gostamos».

Os seguintes dados foram registados na oralidade:

(39) Os filmes que eu mais gosto (= de que) são as comédias.

(40) A rapariga que te falei é a namorada do Pedro (= de quem)

(41) A Joana, a que emprestei o livro, trouxe-o hoje. (= a quem)

(42) Os amigos com que me encontrei são do Porto. (= com quem)

(43) O restaurante que estamos é do meu tio. (= em que)

(44) O cinema que fomos é já antigo. (= a que)

Note-se, curiosamente, que em Inglês, formas como 'whose', 'whom', etc., estão a ser preteridas (pelo menos na oralidade, em situações mais informais, pelos falantes nativos ${ }^{11}$ ) em favor de 'that'. Comprova-se, assim, que a tendência não é exclusiva da língua portuguesa, e sim um fenómeno universal.

\subsection{Outros aspectos já com alguma consistência de mudança (essencialmente na oralidade $)^{12}$}

São, contudo, raramente consideradas em descrições gramaticais, ao contrário das três anteriormente mencionadas:

\subsubsection{Género de vocábulos com terminação em - $a$}

(45) Queria duzentas gramas de fiambre, se faz favor.

1991:

(46) Os botões, que pesavam ao todo sete quilos, encontravam-se numa mala e cada um deles escondia pouco mais de duas gramas de cocaína.

11 Situação que foi confirmada, em várias ocasiões, por Estudantes e Colegas da autora, falantes nativos de Inglês, provenientes de várias regiões do Reino Unido e/ou Estados Unidos.

12 Dados apurados com base na observação de produções de falantes nativos no dia-a-dia. 
1994:

(47) “É pouco lógico aceitar a PJ a imaginar um plano maquiavélico só para capturar Catió", tanto mais que com a captura dos 931 gramas de heroína alguém terá “perdido" milhares de contos.

(Há, em ambos os anos mais abonações, mas em algarismos é difícil, como neste exemplo, entrever o género.)

É, além disso, frequente ouvir-se, em supermercados ou hipermercados, pedir um determinado peso em gramas sempre com a forma feminina. Esta tendência, inexistente no Português brasileiro, em que a grama significa relva, tem sido crescente desde os anos 90, sendo - inclusivamente - olhadas com desconfiança (e até com um ar de reprovação) as pessoas que usam o género correcto: "trezentos gramas". Esta reacção é uma prova de que se efectuou uma mudança no caso deste vocábulo específico ${ }^{13}$.

4.4.2. (Em) + Gerúndio (= depois de, logo que, quando) com a supressão da preposição

As seguintes abonações foram registadas na oralidade, em 2016-2018:

(48) (Em) terminando o jantar, vai fazer os trabalhos de casa.

(49) (Em) chegando a casa telefono-lhe.

(50) (Em) acabando a aula vamos almoçar.

4.4.3. Tempos compostos > tempos simples:

(51) também para acção irreal no passado: "Se eu o visse, dizia-lhe para vir ao cinema connosco" (= Se eu o tivesse visto, tinha-lhe/ter-lhe-ia dito...)

(52) (2) acção que ocorreu: "Embora ela corresse, perdeu o comboio" (Embora ela tivesse /tenha corrido...)

(53) (3) igualmente para acção que não se realizou: "O Pedro já foi embora? Oh, gostava de o ver!" (= de o ter visto)

\section{Variação e Mudança}

A análise destas abonações permitiu verificar a real variação das estruturas mais (do) que e menos (do) que ao longo dos últimos mais de 25 anos, sendo sensível que, entre 1991 e 1994, em termos percentuais, se encontrou um aumento das estruturas com mais que e um uso mais ou menos similar entre menos do que e menos que. 
Comparando estes dados com os apurados em 2016, é altamente significativo o facto de não se atestarem exemplos, nos últimos três meses, destas estruturas com a preposição, sendo exclusivo o emprego de mais que e menos que, pelo menos nos meses de Setembro a Dezembro de 2016. O uso de estruturas sem do é igualmente esmagador em 2018.

Estruturas Comparativas (1991-2016)

\begin{tabular}{c|c|c|c}
\hline ESTRUTURAS & $1^{\circ}$ trimestre 1991 & $1^{\circ}$ trimestre 1994 & Set, Out e Dez 2016 \\
\hline MAIS DO QUE & 64 & 179 & 0 \\
\hline MAIS QUE & 17 & 58 & 118 \\
\hline MENOS DO QUE & 4 & 16 & 0 \\
\hline MENOS QUE & 5 & 16 & 33 \\
\hline
\end{tabular}

No caso da segunda estrutura (Particípios) os dados atestados, ainda que pouco numerosos, comprovam que o uso com o verbo ter se tem generalizado nas últimas décadas (ex. 1991: ter aceite, tenha expulso; 1994: ter aceite, teria aceite, terem aceite, etc.), e ainda mais numeroso em 2016. As formas encontram-se em concorrência e, por isso, é interessante que se ateste, em 21 de Novembro de 2016, um uso desviante da forma "dita tradicional" num contexto em que deveria estar a outra: "Foi no âmbito do seu mestrado que teve acesso aos laboratórios do Imperial College, em Londres, local elegido pela criadora para testar o produto."

Evidencia-se deste modo, na sequência da análise que foi efectuada, que se está a revelar uma efectiva mudança, após um relativamente longo período de variação que já está em curso, pelo menos, nos dados de $1991^{14}$ e, sobretudo, de 1994.

Nas relativas referidas, é clara a simplificação gradual (e foi já assinalada em 1995 por Peres e Móia) para um menor esforço, não só com a supressão da preposição, mas também neutralização em "que".

Quanto aos restantes dados, não se encontraram tantos exemplos no texto escrito, sendo - no entanto - recorrentes na oralidade. Ainda que as descrições gramaticais já os refiram, parecem estar numa fase diferente do processo de mudança, sendo muito menos frequentes no texto escrito.

Está patente a analogia, já verificada em épocas pretéritas do Português, pelo facto de o maior número de palavras terminadas em -a pertencer ao género feminino (o que normalmente constitui uma dificuldade para os aprendentes estrangeiros: cinema, problema, telefonema, etc.), bem como a economia linguística (lei do menor esforço), tanto na preferência por tempos simples em desfavor dos compostos, como na supressão da preposição "em” na estrutura temporal com Gerúndio.

\footnotetext{
14 Não se fornece tabela com dados quantitativos para esta estrutura, uma vez que a pesquisa, com o novo motor de busca, como foi já referido, inviabilizou apurar esses números com rigor. Futuramente, num trabalho mais desenvolvido, e que incluirá outros traços em mudança, procurar-se-á fornecer uma quantificação fiável das variantes para a mencionada estrutura.
} 


\section{Hipóteses de explicação}

Como é normal ao longo da história das línguas, a simplificação de fonemas, flexões, léxico ou estruturas (como é o caso) é um fenómeno que se traduz num menor esforço para o falante quando existe uma (aparente) redundância ou coexistência de usos ou formas, por vezes consideradas como opcionais. Deste modo, parece claro que os falantes nativos sentem como perfeitamente adequada a estrutura simplificada ("cortada"), pelo que preferem (claramente, nos nossos dias) quase exclusivamente o seu uso em desfavor de mais / menos do que. A razão pela qual uma das estruturas parece mais afectada pela variação do que a outra poderá prender-se com o facto de se tratar de um monossílabo (mais), permitindo, assim, um menor esforço articulatório. Esta "lei do menor esforço" explica também por que razão a forma mais "curta” do particípio passado - a que normativamente se usaria com os verbos ser, estar e ficar - se encontra em franca preferência em detrimento da tradicional em -ado/-ido.

Quanto a este uso das formas de Particípio, então, a supra mencionada explicação de Raposo et al. parece adequar-se aos dados e ao que diariamente ouvimos/lemos. Parece haver, de facto, um «efeito de bloqueio» pela existência das duas formas e, portanto, uma «nivelação analógica», que se traduz por utilizar com ter as formas que se usam com o maior número de verbos (estar, ser e ficar).

O mesmo ocorre com o relativo: de/com/a/por/para que em lugar de a/de/com/por/para quem.

Nos restantes casos, a analogia com o género das palavras com terminação - a e, uma vez mais, a economia linguística (lei do menor esforço) são os motivos para a variação actualmente existente e que anuncia uma mudança em curso com alguma vitalidade.

Prova-se, deste modo, que existem, hoje em dia, claríssimas variações a ocorrer na língua portuguesa e que algumas delas estão a merecer uma plena aceitação por parte da comunidade, mesmo a mais culta e prestigiada. Ou seja, está em curso um processo de efectiva mudança linguística.

\section{Considerações finais}

É muito possível que, como é usual na mudança linguística (Coseriu 1958), a génese da variação tenha ocorrido primeiro na oralidade, sendo a sua atestação na escrita uma prova de hesitação ou facultatividade no emprego destas estruturas (encaradas como opcionais, em todos os estratos sociais/socioculturais e camadas etárias) ou vocábulos.

Essa variação que se veio, paulatinamente, ampliando ${ }^{15}$, está agora a tomar um rumo de fixação cada vez mais frequente na estrutura com "estratégia cortadora", em mais do que um dos casos analisados, de simplificação ("economia") e de analogia.

Os dados analisados, e a percentagem crescente de atestações sem do no segundo segmento da comparação (curiosamente mais próximas da língua latina e do português antigo), de cada vez mais usos das formas não tradicionais do Particípio com o auxiliar ter, ou de "neutralização" dos relativos em que, por exemplo, comprovam que - pela aceitação geral da comunidade linguística portuguesa - está a processar-se a mudança, no seu último momento, que é o da generalização / 
aceitação e atribuição de prestígio a uma das estruturas concorrentes, tanto mais que, no corpus utilizado, as produções pertencem a falantes/escreventes com escolarização média-alta e, não raras vezes, superior, uma vez que se trata de jornalistas, comentadores, etc., com formação académica.

Os dados a que se chegou podem igualmente ser úteis para o ensino do Português como Língua Não Materna, uma vez que não fará muito sentido exigir que os aprendentes sigam as regras estipuladas para estas estruturas, quando o dia-a-dia prova precisamente que elas estão a ser abandonadas.

O que deve, então, fazer o professor de língua portuguesa ao ensinar estas particularidades/ estruturas? Convém, por isso, ao ensinar os usos "canónicos", aqueles que correspondem à norma, alertar para o processo de mudança em efectivação, com o qual os aprendentes irão contactar na linguagem quotidiana, que paulatinamente se afasta das regras que a gramática normativa enunciava. É importante explicar que, nalguns contextos ou situações, pode haver variação, mesmo em falantes cultos.

Há que ter em atenção que há diferenças se está a ensinar a pessoas que se encontram num contexto de imersão (contactam com os vários níveis de língua diariamente) ou se se trata de aprendentes que se localizam num país estrangeiro, com menor exposição à língua de aprendizagem. Por outro lado, a explicação deve ser tanto mais precisa quanto mais elevado é o nível de proficiência do aprendente.

Por último, é importante a consciencialização de que as línguas vivas variam e mudam, e o Português não é, certamente, excepção.

\section{Referências bibliográficas}

Bechara, E. (2001). Moderna gramática portuguesa. 37ª ed. revista e ampliada. Rio de Janeiro: Editora Lucerna.

Coseriu, E. (1978 [1958]). Sincronía, diacronía e historia. El problema del cambio lingüístico. $3^{\text {a }}$ ed. Madrid: Gredos.

Cunha, C.; \& Cintra L. F. L. (1984). Nova gramática do português contemporâneo. $4^{\mathrm{a}}$ ed. Lisboa: Edições João Sá da Costa.

Ferreira, C. S. (2013). Usos do particípio passado duplo no português europeu contemporâneo: padrões de variação numa amostra de população escolar. Tese de Doutoramento. Universidade de Coimbra.

Gouveia, M. C. F. (2008). O género gramatical do português: da teoria à prática. Análise da atribuição de género por alunos do $1^{\circ}$ Ciclo Universitário. Biblos. Revista da Faculdade de Letras, VI (II série), 221-250.

. (2011). O género de alguns vocábulos "problemáticos" do português contemporâneo. Revista

Mundo \& Letras, 2, 85-97. <http://www.revistamundoeletras.com.br/artigos2011/2011_Artigo07.pdf>

Mateus, M. H. M. et al. (2003). Gramática da língua portuguesa, $6^{a}$ ed. Lisboa: Editorial Caminho.

Peres, J. A.; \& Móia, T. (1995). Áreas críticas da língua portuguesa. Lisboa: Editorial Caminho.

Raposo, E. B. P. et al. (2013). Gramática do Português. 2 vols. Lisboa: Fundação Calouste Gulbenkian. 
Silva, A. A. (2003). Uma perspectiva funcional da estrutura comparativa. In A. Mendes, \& T. Freitas (Eds.), Actas do XVIII Encontro da Associação Portuguesa de Linguística. (pp. 743-754). Lisboa: Associação Portuguesa de Linguística.

Vilela, M. (1999). Gramática da língua portuguesa: gramática da palavra, gramática da frase e gramática do texto/discurso. $2^{\text {a }}$ ed. Coimbra: Livraria Almedina.

Weinreich, U.; Labov, W.; \& Herzog, M. I. (1968). Empirical Foundations for a Theory of Language Change. In W. P. Lehmann, \& Y. Malkiel (Eds.), Directions for Historical Linguistics. A Symposium, 3a ed. (pp. 95-188. Austin: University of Texas Press. 
